\title{
Long-term clinical outcomes in patients with viral hepatitis related liver cirrhosis after transjugular intrahepatic portosystemic shunt treatment
}

\author{
Dengke Teng ${ }^{1}$, Hao Zuo², Lin Liư ${ }^{3}$, Jinghui Dong ${ }^{4^{*}}$ and Lei Ding ${ }^{3^{*}}$
}

\begin{abstract}
Background: Transjugular intrahepatic portosystemic shunt (TIPS) procedure has played a vital role in management of portal hypertension. Thus, we aimed to investigate the natural history, long-term clinical outcome, predictors of survival in viral hepatitis related cirrhotic patients post-TIPS.

Method: A total of 704 patients with complete followed-up data were enrolled, and clinical characteristics of patients were collected and analyzed. Kaplan-Meier method was used to calculate survival, and comparisons were made by log rank test. A multivariate analysis of factors influencing survival was carried out using the Cox proportional hazards regression model.

Results: TIPS implatantion significantly decreased portal vein pressure with $9.77 \mathrm{cmH}_{2} \mathrm{O}$ reduction, without influencing long-term liver functions. The total incidence rate of major complication post-TIPS, including HE and re-bleeding/bleeding, was $37.9 \%$ and $15.5 \%$, respectively. Patients in Child-Pugh C stage revealed higher overt hepatic encephalopathy (HE) occurrence (65.6\%), while patients receiving covered, $6 \mathrm{~mm}$ in diameter stents indicated notably lower incidence of HE in comparison with other groups (6.4\%). The median survival was $>60$ months, 27.0 months, and 11.5 months in cirrhotic patients with variceal bleeding, refractory ascites, and both complications, respectively. The cumulative 5-year survival was significantly higher in patients with variceal bleeding (75.6\%) in comparison with either that in patients with refractory ascites $(12.5 \%)$ or that in patients with both complications (1.96\%) $(P<0.0001)$. Covered stents usage, baseline model for end-stage liver disease (MELD) score, and baseline Child-Pugh classification were predictive of survival $(P<0.001)$. Other variables including age, male gender, and pre-TIPS PVP were not emerged as significant predictors $(P>0.05)$.
\end{abstract}

Conclusion: TIPS was an effective and safe therapeutic method for decompression of portal hypertension and for treatment of its complications. Careful selection of patients with minimal liver dysfunction for TIPS implantation was essential for better long-term outcomes.

Keywords: Transjugular intrahepatic portosystemic shunt, Liver cirrhosis, Portal hypertension, Refractory ascites, Variceal bleeding

\footnotetext{
*Correspondence: dongjinghui302@126.com; zr_dingl@163.com

${ }^{4}$ Department of Radiology, 302 Military Hospital of China, 100 West Fourth

Ring Rd, Beijing 100039, China

${ }^{3}$ Department of Radiology, China-Japan Union Hospital of Jilin University, 126

Xintai St, Changchun 130022, Jilin Province, China

Full list of author information is available at the end of the article
}

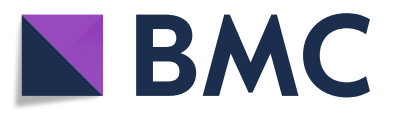

(c) The Author(s). 2018 Open Access This article is distributed under the terms of the Creative Commons Attribution 4.0 International License (http://creativecommons.org/licenses/by/4.0/), which permits unrestricted use, distribution, and reproduction in any medium, provided you give appropriate credit to the original author(s) and the source, provide a link to the Creative Commons license, and indicate if changes were made. The Creative Commons Public Domain Dedication waiver (http://creativecommons.org/publicdomain/zero/1.0/) applies to the data made available in this article, unless otherwise stated. 


\section{Background}

Portal hypertension is one of the most common problems among patients with liver cirrhosis, and therapeutic approaches of the complications are still the challenging tasks [1, 2]. Development of portal hypertension always results in the formation of collateral circulation in portal vein system, which leads to the portal venous flow into systemic circulation and directly increase the incidence of several clinical consequences, e.g. variceal bleeding and refractory ascites [3-7]. Although a variety of treatment methods have been built up, controversy remains as to the most effective therapeutic algorithm for the complications of portal hypertension $[8,9]$.

Transjugular intrahepatic portosystemic shunt (TIPS) surgery inserted metal stent into the liver parenchyma radiologically to establish a shunt between portal vein and hepatic vein/inferior vena cava. It is an efficient method for reducing portal pressure, and has been widely used for treatment of complications of portal hypertension [10, 11]. TIPS has gradually become the first-line therapeutic choice for cirrhotic patients with acute variceal hemorrhage who failed with endoscopic hemostasis $[12,13]$, with an estimated technical successful rate of $93-100 \%$ [2]. TIPS is also used in treatment of refractory ascites [14-16] and hepatorenal syndrome [17] due to the circulatory effects on portal hypertension. However, there have been concerns about TIPS implantation, especially with high rate of hepatic encephalopathy (HE) post-TIPS [14]. More recently, the development and usage of covered metal stents significantly reduce the shunt dysfunction in comparison with bare mental stents insertion [18], leading to the lower occlusion rate of consecutive bleeding and improvement of overall survival $[19,20]$. However, few studies focused on the long-term outcomes of patients receiving TIPS for complications of portal hypertension and liver cirrhosis, especially with respect to variceal bleeding versus refractory ascites. Thus, in this retrospective study, we evaluated the long-term efficacy and outcomes of TIPS in treatment of variceal bleeding and/or refractory ascites. The major objectives of the present study were to observe the occurrence of clinical complications of TIPS, and predictors of survival.

\section{Methods}

\section{Patients and followed-up}

We screened integrated database which included a total of 1024 patients with viral hepatitis related liver cirrhosis who underwent TIPS insertion between June 2004 and December 2012 in China-Japan Union Hospital and 302 Military Hospital. The indication for TIPS treatment included acute or recurrent variceal bleeding and refractory ascites. TIPS insertion was technically not feasible in 89 patients, including 46 patients with unsuccessful portal vein puncture, 28 patients with portal vein malformation, and 15 patients with portal vein thrombosis. There were 231 cases who were lost to follow-up after TIPS insertion. Thus, eventually 704 patients with complete 5-year followed-up data or confirmed death within 5-year followed-up period were enrolled in this study. The TIPS procedures were accomplished by different specialists followed with the same protocol. Anticoagulant drugs, ornithine aspartate, and lactulose were routinely used after TIPS insertion. All patients were treated for primary diseases in the followed-up period, such as nucleos(t)ide analogue therapy for HBV infection. Followed-up data were obtained by in-patients/ out-patients visit, or telephone calls every year. Biochemical and ultrasound assessments were performed as routine examination. The study protocol was approved by Ethics Committees of both China-Japan Union Hospital and 302 Military Hospital on December 2016, and data were collected on January and February 2017.

\section{Assessment of clinical characteristics}

TIPS procedures were conducted using standard techniques [21]. Serum biochemical assessments (including alanine aminotransferase [ALT], aspartate aminotransferase $[A S T]$, albumin $[A L B]$, total bilirubin [T-BIL], blood urea nitrogen $[\mathrm{BUN}]$, and serum creatinine $[\mathrm{Cr}]$ ) were measured using an automatic analyzer (Hitachi 7170A, Hitachi Ltd., Tokyo, Japan). Coagulation function (including prothrombin time [PT], thrombin time [TT], activated partial thromboplastin time [APTT], fibrinogen [Fib], prothrombin activity [PTA], and international normalized ratio [INR]) were measured using a coagulation analyzer (PUN-2048, Perlong Medical Products, Beijing, China). Abdominal ultrasound examination was measured using a Doppler ultrasound diagnostic apparatus (NemioXG, Toshiba, Tokyo, Japan). The stiffness of liver was measured using FibroScan 502 (Echosens, Pairs, France). The severity of liver disease was assessed using traditional Child-Pugh classification as described previously [22, 23]. T-BIL, ALB, INR, ascites, and HE grade was involved for Child-Pugh scoring.

\section{Statistical analysis}

All data were analyzed using SPSS version 19.0 for Windows Software (SPSS Inc., Chicago, IL, USA). Wilcoxon's matched pairs test or Dunn's multiple comparison test were used for comparison of quantitative data. Chisquared test was used for comparison of categorical data. Kaplan-Meier method was employed to calculate survival from the time of TIPS treatment, and comparisons were made by log rank test. A multivariate analysis of factors influencing survival was carried out using the Cox proportional hazards regression model. The potential predictor variables for survival was age, male gender, 
and pre-TIPS PVP, complications, stents usage, model for end-stage liver disease (MELD) score, and ChildPugh classification. We firstly perform univariate analysis for each variable and then perform multivariate analysis using all the variables. All tests were two-tailed, and $P$ values of less than 0.05 were considered to indicate significant differences.

\section{Results}

\section{Baseline characteristics of enrolled patients}

The retrospective cohort comprised 704 of liver cirrhotic patients with TIPS insertion. Baseline characteristics of enrolled patients were listed in Table 1 . Of these patients, $581(82.5 \%)$ showed variceal bleeding, 72 (10.2\%) revealed refractory ascites, whereas 51 (7.3\%) demonstrated both variceal bleeding and refractory ascites. Five hundred and eleven (72.6\%) patients were male and 193 (27.4\%) were female, with a mean age of 53.2 years.

\section{TIPS insertion significantly reduced PVP of patients with} liver cirrhosis, but not ameliorated liver functions In all 704 enrolled patients with TIPS treatment, direct measurements of portal vein pressure (PVP) were carried out in 487 cases before and after stent insertion. TIPS insertion significantly decreased PVP with 9.77 $\mathrm{cmH}_{2} \mathrm{O}$ reduction $\left(36.81 \pm 8.68 \mathrm{cmH}_{2} \mathrm{O}\right.$ vs. $27.04 \pm 7.79$ $\mathrm{cmH}_{2} \mathrm{O}$, Wilcoxon's matched pairs test, $\left.P<0.0001\right)$. All patients were also received anti-fibrosis and anti-primary

Table 1 Baseline clinical characteristics of enrolled patients

\begin{tabular}{ll}
\hline Characteristic & Value \\
\hline Patients enrolled ( $n$ ) & 704 \\
Variceal bleeding & 581 \\
Refractory ascites & 72 \\
Variceal bleeding and refractory ascites & 51 \\
Age, years, (mean \pm SD) & $53.2 \pm 13.6$ \\
Gender, male/female, $(n)$ & $511 / 193$ \\
Cause of cirrhosis ( $n$ ) & \\
HBV & 509 \\
HCV & 134 \\
HBV + HCV & 52 \\
HBV + HDV & 9 \\
Child-Pugh classification ( $n$ ) & \\
A & 219 \\
B & 421 \\
C & 64 \\
MELD score, (mean $\pm S D)$ & $12.8 \pm 5.1$ \\
Stiffness of liver, KPa, (mean \pm SD) & $18.6 \pm 10.7$ \\
Diameter of portal vein, $\mathrm{Cm}$, (mean \pm SD) & $1.52 \pm 0.37$ \\
Diameter of splenic vein, $\mathrm{cm}$, (mean $\pm S D)$ & $0.96 \pm 0.21$ \\
\hline
\end{tabular}

MELD model for end-stage liver disease diseases therapies, and liver functions were assessed in each visit. There were no remarkable differences in ALT, T-BIL, albumin, and stiffness of liver after TIPS insertion in comparison with baseline (Dunn's multiple comparison test, $P>0.05$, Table 2 ). All patients were routinely treated with anticoagulant drugs at a weight-dependent dose for 1 year after TIPS insertion, leading to the disturbance of blood coagulation which presented as the reduction in PTA and elevation in INR (Dunn's multiple comparison test, $P<0.05$ compared with baseline, Table 2 ). However, blood ammonia was also increased, especially in the early stage after TIPS implantation, although ornithine aspartate were routinely used (Dunn's multiple comparison test, $P<0.05$ compared with baseline, Table 2).

\section{Complications after TIPS implantation}

The major complications after TIPS therapy included $\mathrm{HE}$ and re-bleeding/bleeding. The total incident rate of HE and re-bleeding/bleeding was $37.9 \%$ and $15.5 \%$, respectively. Patients with variceal bleeding and refractory ascites indicated higher incidences for both $\mathrm{HE}$ and re-bleeding/bleeding (Chi-squared test, $P<0.05$, Table 3). Patients with Child-Pugh $C$ revealed a significant elevated incidence of $\mathrm{HE}$ than those with Child-Pugh A or B (Chi-squared test, $P<0.01$, Table 3 ). However, there were no remarkable difference in the incidence of re-bleeding/bleeding among Child-Pugh classification (Chi-squared test, $P>0.05$, Table 3 ). Moreover, uncovered $(n=130)$ and covered $(n=574)$ metal stents were used for portosystemic shunt. No significant incidence of $\mathrm{HE}$ and re-bleeding/bleeding were found between patients using uncovered and covered stents (Chi-squared test, $P>0.05$, Table 3 ). However, patients receiving covered, $6 \mathrm{~mm}$ in diameter stents indicated notably lower incidence of $\mathrm{HE}$ in comparison with other groups (Chi-squared test, $P<0.0001$, Table 3 ).

\section{Patients survival}

Overall median survival was $>60$ months with the cumulative 5-year survival of patients in $63.6 \%$ (Fig. 1a). The median survival was $>60$ months, 27.0 months, and 11.5 months in cirrhotic patients with variceal bleeding, refractory ascites, and both complications, respectively. Moreover, the cumulative 5 -year survival was significantly higher in patients with variceal bleeding (75.6\%) in comparison with either that in patients with refractory ascites $(12.5 \%$, hazard ratio $[\mathrm{HR}]=69.28[95 \% \mathrm{CI}$ 39.01-123.0], $P<0.0001$, Fig. 1b) or that in patients with both complications $(1.96 \%, \quad H R=0.00025 \quad[95 \%$ CI 0.00011-0.00059], $P<0.0001$, Fig. 1b). On multivariate analysis covered stents usage $(\mathrm{HR}=2.96$ [95\% CI 2.064.25], $P<0.0001$, Fig. 1c), baseline MELD score (HR = 0.40 [95\% CI 0.31-0.41], $P<0.0001$, Fig. 1d), and baseline Child-Pugh classification (Child-Pugh A versus 
Table 2 Changes in liver functions of liver cirrhotic patients with TIPS treatment

\begin{tabular}{lllllll}
\hline & $\begin{array}{l}\text { Baseline } \\
(n=704)\end{array}$ & $\begin{array}{l}1 \text { year } \\
(n=638)\end{array}$ & $\begin{array}{l}2 \text { years } \\
(n=587)\end{array}$ & $\begin{array}{l}3 \text { years } \\
(n=530)\end{array}$ & $\begin{array}{l}4 \text { years } \\
(n=485)\end{array}$ & $\begin{array}{l}5 \text { years } \\
(n=445)\end{array}$ \\
\hline ALT $(\mathrm{U} / \mathrm{L})$ & $51 \pm 28$ & $47 \pm 19$ & $55 \pm 31$ & $52 \pm 21$ & $58 \pm 20$ & $55 \pm 18$ \\
T-BIL $(\mu \mathrm{mol} / \mathrm{L})$ & $29.2 \pm 19.7$ & $34.8 \pm 20.1$ & $32.9 \pm 21.8$ & $35.9 \pm 20.8$ & $34.6 \pm 19.7$ & $27.6 \pm 18.0$ \\
Albumin $(\mathrm{g} / \mathrm{L})$ & $28.9 \pm 10.2$ & $29.1 \pm 11.7$ & $30.0 \pm 9.8$ & $28.7 \pm 8.2$ & $29.7 \pm 9.2$ & $30.1 \pm 12.8$ \\
Blood ammonia ( $\mu \mathrm{mol} / \mathrm{L})$ & $64.7 \pm 25.9$ & $87.6 \pm 27.1^{\# \#}$ & $81.5 \pm 19.8^{\# \#}$ & $76.2 \pm 20.5^{\# \#}$ & $78.2 \pm 21.2$ & $71.0 \pm 11.6$ \\
PTA (\%) & $56.8 \pm 12.5$ & $37.8 \pm 9.1^{\#}$ & $51.4 \pm 8.7$ & $49.2 \pm 11.0$ & $50.1 \pm 10.2$ & $50.8 \pm 8.9$ \\
INR & $1.36 \pm 0.23$ & $1.90 \pm 0.46^{\#}$ & $1.48 \pm 0.51$ & $1.50 \pm 0.49$ & $1.50 \pm 0.44$ & $1.47 \pm 0.38$ \\
Stiffness (KPa) & $18.6 \pm 10.7$ & $17.6 \pm 9.8$ & $17.9 \pm 12.7$ & $16.8 \pm 8.6$ & $16.7 \pm 9.1$ & $17.1 \pm 10.2$ \\
\hline P & & & &
\end{tabular}

${ }^{\#} P<0.05,{ }^{\# \#} P<0.01$ compared with baseline, Dunn's multiple comparison test

Child-Pugh B, HR $=0.73$ [95\% CI 0.54-0.98], $P=0.038$; Child-Pugh A versus Child-Pugh C, HR $=0.034[95 \%$ CI 0.019-0.058], $P<0.0001$; Child-Pugh $B$ versus ChildPugh C, HR $=0.038$ [95\% CI 0.023-0.064], $P<0.0001$; Fig. 1e) were predictive of survival. Other variables included in the final Cox proportional hazards model were age, male gender, and pre-TIPS PVP, but none emerged as significant predictors $(P>0.05)$.

\section{Discussion}

To the best of our knowledge, the current study represented one of the largest cohort of patients who received TIPS as therapeutic method for the complications of portal hypertension and liver cirrhosis, and followed-up for the longest period of time, thereby allowing us to better understand plenty of issues related to TIPS implantation for variceal bleeding and/or refractory ascites.
In this retrospective study, shunt insertion was successful in 91.3\% (935/1024) of patients scheduled. The baseline characteristics revealed that distribution of underlying diseases was typical for China, with chronic viral hepatitis as the major causation for liver cirrhosis [24]. In agreement with previous findings [25-28], we confirmed that TIPS is effective as treatment for variceal bleeding and refractory ascites in cirrhotic patients without improvement of liver function. TIPS implantation could decrease the portal pressure gradient by $20-50 \%$ of the initial pressure, and maintained under $12 \mathrm{mmHg}$ $[29,30]$. This was consistent with the current results of reduction in direct measurement of PVP. However, there were no remarkable differences in the degree of reduction of PVP post-TIPS insertion among patients with variceal bleeding and/or refractory ascites. Although the initial reduction in PVP after TIPS insertion was considered to be a predictor for rebleeding risk, but not for

Table 3 The incidence of major complications after TIPS treatment

\begin{tabular}{lll}
\hline & HE & Re-bleeding/Bleeding \\
\hline Total & $267 / 704(37.9 \%)$ & $109 / 704(15.5 \%)$ \\
Variceal bleeding & $208 / 581(35.8 \%)$ & $81 / 581(13.9 \%)$ \\
Refractory ascites & $31 / 72(43.1 \%)$ & $6 / 72(8.3 \%)$ \\
Variceal bleeding and refractory ascites & $28 / 51(54.9 \%)$ & $22 / 51(43.1 \%)$ \\
Child-Pugh classification & & $37 / 219(16.9 \%)$ \\
A & $83 / 219(37.8 \%)$ & $61 / 421(14.5 \%)$ \\
B & $142 / 421(33.7 \%)$ & $11 / 64(17.2 \%)$ \\
C & $42 / 64(65.6 \%)$ & \\
Type of stent & & $17 / 130(13.1 \%)$ \\
Uncovered stent $(n=130)$ & $56 / 130(43.1 \%)$ & $5 / 47(10.6 \%)$ \\
$\quad$ Diameter of stent $=8 \mathrm{~mm}(n=47)$ & $17 / 47(36.1 \%)$ & $12 / 83(14.5 \%)$ \\
Diameter of stent $=10 \mathrm{~mm}(n=83)$ & $39 / 83(47.0 \%)$ & $92 / 574(16.0 \%)$ \\
Covered stent $(n=574)$ & $211 / 574(36.8 \%)$ & $14 / 94(14.9 \%)$ \\
$\quad$ Diameter of stent $=6 \mathrm{~mm}(n=94)$ & $6 / 94(6.4 \%)$ & $31 / 178(17.4 \%)$ \\
$\quad$ Diameter of stent $=7 \mathrm{~mm}(n=178)$ & $67 / 178(37.6 \%)$ & $47 / 302(15.6 \%)$ \\
Diameter of stent $=8 \mathrm{~mm}(n=302)$ & $138 / 302(45.7 \%)$ & \\
\hline
\end{tabular}

${ }^{\#} P<0.05, " \# P<0.01$, and ${ }^{\# \# \#} P<0.01$ compared with other groups, Chi-squared test 

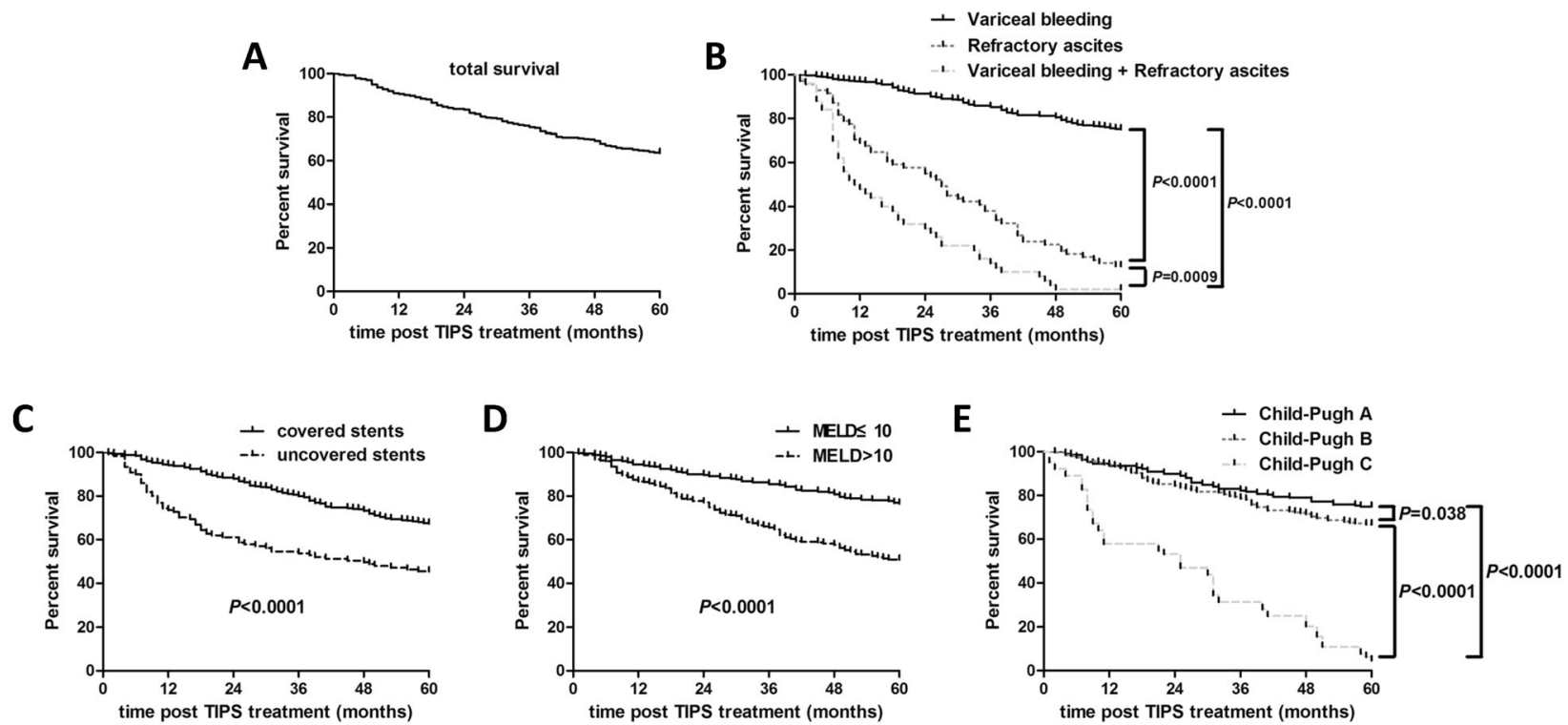

Fig. 1 Kaplan-Meier survival analysis of patients after transjugular intrahepatic portosystemic shunt (TIPS) implantation. a Overall survival. b Comparison of probability of survival among patients with variceal bleeding and/or refractory ascites. c Comparison of probability of survival between patients with uncovered and covered stent. $\mathbf{d}$ Comparison of probability of survival between patients with baseline MELD score $\leq 10$ and $>10$. e Comparison of probability of survival among patients with different Child-Pugh stage

survival [31], we did not find notable correlation between baseline/reduction of PVP and survival, indicating that PVG might not be the predictor for survival post-TIPS treatment.

In consistent with Membreno et al. [32] and Heinzow et al. [2], the current results demonstrated that overall long-term survival was significantly better in patients with TIPS due to variceal bleeding (>60 months) than that in patients with TIPS due to refractory ascites (27.0 months), while the combination of both complications further worsened the survival (11.5 months, $P<$ 0.001 ) with higher rate of major complications. The overall occurrence of HE was nearly $40 \%$ which was higher than previous reports, although we routinely prescribed ornithine aspartate and lactulose to all patients post-TIPS. The use of smaller diameter stents might be associated with lower risk of HE post-TIPS, as the development of refractory HE requiring reduction in shunt diameter in $8-10 \%$ of patients [33]. This was in accordance with our results showing the lower HE occurrence in patients with $6 \mathrm{~mm}$-diameter of stent insertion, although elevated risk of treatment failure was also observed among patients with smaller 8-mm stent from a randomized controlled trials [34].

TIPS implantation increased the risk of acute liver and/or cardiac decompensation and failure. Thus, careful selection of patients with liver cirrhosis and portal hypertension was crucial to the successful outcome post-TIPS [35, 36]. Previous study revealed that better liver function might respond better to TIPS insertion
[37]. The baseline age $<55$ years, $\mathrm{T}-\mathrm{BIL}<35 \mu \mathrm{mol} / \mathrm{L}$, and serum sodium $>135 \mathrm{mmol} / \mathrm{L}$ indicated beneficial survival post-TIPS. Original Child-Pugh stage [2], modified Child-Na score with serum sodium incorporation [38], and MELD score [39] were independent prognostic factor of survival. We showed that patients in Child-Pugh C stage demonstrated higher incidence of overt HE. Moreover, in agreement with previous findings, ChildPugh stage and MELD score were significant indicator for survival post-TIPS, probably due to the fact that both scoring systems were validated tools for assessing prognosis [40]. Thus, approximate $60 \%$ of overall 5 -year survival was not surprising as the enrolled patients had minimal liver dysfunction at baseline.

Uncovered metal stents were one of the treatment choice for establishing TIPS tracts [41], with approximate $20 \%$ use of all TIPS procedures in United States [42]. The higher rate of shunt dysfunction with consecutive bleeding complications [43] has been largely overcome after the development of covered metal stents [18, 19, 44]. Although Bureau and colleagues did not detect survival benefit of covered and bare stents [45], more recently meta-analyses of randomized controlled trials revealed that covered stents for TIPS improved overall survival [20], especially in prevention of variceal re-bleeding [46]. In addition, it was also reported that 1-year probability of remaining free of $\mathrm{HE}$ in patients with post-covered TIPS was numerically lower than that with bare stents $[35,47]$. In the present study, we found that there were no remarkable differences in the 
occurrences of either HE or re-bleeding between covered and uncovered stents. Furthermore, the use of covered stents was predictive of beneficial survival, which was similar to the findings by Tan et al. in refractory ascites [35]. This was partly due to the better baseline liver function in covered stents groups, which was also found in Tan's study [35]. Moreover, since most covered stents were used in recent years, the improvement in procedurerelated skills with primary patency up to $90 \%$ within first year application also accounted for superiority of covered stents $[19,35]$. Thus, as expected, the improved survival was due to era effect rather than type of stents [35], which further deepened the understanding of patients selection for TIPS implantation.

There were some limitations in this study. First, we conducted a retrospective study with limited patients numbers and no control group was established. Thus, large-scale, random control studies were needed to confirm the current results. Second, we tried to identify predictors for liver failure in patients post-TIPS. However, the definition for liver failure was hard. The classical definition for liver failure contains jaundice (T-BIL $>170 \mu \mathrm{mol} / \mathrm{L}$ ) and coagulopathy $(\mathrm{PTA}<40 \%$ ). The use of anticoagulant drugs down-regulated PTA level, which made it hard for definition. Furthermore, only few patients suffered with high jaundice post-TIPS. Thus, we did not analyze predictors for liver failure post-TIPS. Third, the factors regarding the cause of cirrhosis were lacking in survival analysis after TIPS. Fourth, the cause of death of patients did not analyzed in the current study.

\section{Conclusion}

TIPS was an effective and safe therapeutic method for decompression of portal hypertension and for treatment of its complications. Child-Pugh stage and MELD score were independent predictors of survival in patients with TIPS implantation. Thus, careful selection of patients for TIPS was essential for better long-term outcomes.

\footnotetext{
Abbreviations

ALT: Alanine aminotransferase; APTT: Activated partial thromboplastin time; AST: Aspartate aminotransferas; BUN: Blood urea nitrogen; Cr: Creatinine; Fib: Fibrinogen; HE: Hepatic encephalopathy; HR: Hazard ratio; INR: International normalized ratio; MELD: Model for end-stage liver disease; PT: Prothrombin time; PTA: Prothrombin activity; PVP: Portal vein pressure; TBIL: Total bilirubin; TIPS: Transjugular intrahepatic portosystemic shunt; TT: Thrombin time
}

\section{Authors' contributions}

JD designed and supervised the study. LD, DT, and LL acquisition of data. $L D, D T, H Z, L L$, and JD analyzed and interpreted the data. LD, DT, HZ, and JD prepared the manuscript. All authors read and approved the final manuscript.

\section{Ethics approval and consent to participate}

The study protocol was approved by Ethics Committees of both China-Japan Union Hospital and 302 Military Hospital on December 2016.
Consent for publication

Not applicable.

\section{Competing interests}

The authors declare that they have no competing interests.

\section{Publisher's Note}

Springer Nature remains neutral with regard to jurisdictional claims in published maps and institutional affiliations.

\section{Author details}

'Department of Ultrasound, China-Japan Union Hospital of Jilin University, Changchun 130022, Jilin Province, China. ${ }^{2}$ Department of Pain, The Second Hospital of Jilin University, Changchun 130041, Jilin Province, China. ${ }^{3}$ Department of Radiology, China-Japan Union Hospital of Jilin University, 126 Xintai St, Changchun 130022, Jilin Province, China. ${ }^{4}$ Department of Radiology, 302 Military Hospital of China, 100 West Fourth Ring Rd, Beijing 100039, China

Received: 14 June 2018 Accepted: 25 September 2018

Published online: 01 October 2018

\section{References}

1. Siramolpiwat S. Transjugular intrahepatic portosystemic shunts and portal hypertension-related complications. World J Gastroenterol. 2014 20:16996-7010.

2. Heinzow HS, Lenz $P$, Kohler $M$, Reinecke $F$, Ullerich $H$, Domschke $W$, Domagk D, Meister T. Clinical outcome and predictors of survival after TIPS insertion in patients with liver cirrhosis. World I Gastroenterol. 2012;18:5211-8.

3. Ertel AE, Chang AL, Kim Y, Shah SA. Management of gastrointestinal bleeding in patients with cirrhosis. Curr Probl Surg. 2016;53:366-95.

4. Toshikuni N, Takuma Y, Tsutsumi M. Management of gastroesophageal varices in cirrhotic patients: current status and future directions. Ann Hepatol. 2016;15:314-25.

5. Williams MJ, Hayes P. Improving the management of gastrointestinal bleeding in patients with cirrhosis. Expert Rev Gastroenterol Hepatol. 2016;10:505-15

6. Garcia-Tsao G, Sanyal AJ, Grace ND, Carey W, Practice guidelines Committee of the American Association for the study of liver $D$ practice parameters Committee of the American College of $\mathrm{G}$. Prevention and management of gastroesophageal varices and variceal hemorrhage in cirrhosis. Hepatology. 2007:46:922-38.

7. Sanyal AJ, Bosch J, Blei A, Arroyo V. Portal hypertension and its complications. Gastroenterology. 2008;134:1715-28.

8. Garcia-Tsao G. Current Management of the Complications of cirrhosis and portal hypertension: variceal hemorrhage, ascites, and spontaneous bacterial peritonitis. Dig Dis. 2016;34:382-6.

9. Nguyen GC, Segev DL, Thuluvath PJ. Racial disparities in the management of hospitalized patients with cirrhosis and complications of portal hypertension: a national study. Hepatology. 2007:45:1282-9.

10. Tytle $T L$, Loeffler $C$, Thompson WM 3rd. Transjugular intrahepatic portosystemic shunt (TIPS): a promising nonsurgical treatment for bleeding gastroesophageal varices. J Okla State Med Assoc. 1993;86:220-4.

11. Sanyal AJ, Genning C, Reddy KR, Wong F, Kowdley KV, Benner K, McCashland T, North American study for the treatment of refractory ascites $\mathrm{G}$. The north American study for the treatment of refractory ascites. Gastroenterology. 2003;124:634-41.

12. Goykhman Y, Ben-Haim M, Rosen G, Carmiel-Haggai M, Oren R, Nakache R, Szold O, Klausner J, Kori I. Transjugular intrahepatic portosystemic shunt: current indications, patient selection and results. Isr Med Assoc J. 2010;12:687-91.

13. Boyer TD, Haskal ZJ, American Association for the Study of liver D. The role of Transjugular intrahepatic portosystemic shunt (TIPS) in the Management of Portal Hypertension: update 2009. Hepatology. 2010;51:306.

14. Forrest EH, Stanley AJ, Redhead DN, McGilchrist AJ, Hayes PC. Clinical response after transjugular intrahepatic portosystemic stent shunt insertion for refractory ascites in cirrhosis. Aliment Pharmacol Ther. 1996;10:801-6.

15. Ochs A, Rossle M, Haag K, Hauenstein KH, Deibert P, Siegerstetter V Huonker M, Langer M, Blum HE. The transjugular intrahepatic portosystemic stent-shunt procedure for refractory ascites. N Engl J Med. 1995;332:1192-7. 
16. Narahara $Y$, Kanazawa $H$, Fukuda $T$, Matsushita $Y$, Harimoto $H$, Kidokoro H, Katakura T, Atsukawa M, Taki Y, Kimura Y, et al. Transjugular intrahepatic portosystemic shunt versus paracentesis plus albumin in patients with refractory ascites who have good hepatic and renal function: a prospective randomized trial. J Gastroenterol. 2011;46:78-85.

17. Anderson CL, Saad WE, Kalagher SD, Caldwell S, Sabri S, Turba UC, Matsumoto AH, Angle JF. Effect of transjugular intrahepatic portosystemic shunt placement on renal function: a 7-year, singlecenter experience. J Vasc Interv Radiol. 2010;21:1370-6.

18. Perarnau JM, Le Gouge A, Nicolas C, d'Alteroche L, Borentain P, Saliba F, Minello A, Anty R, Chagneau-Derrode C, Bernard PH, et al. Covered vs. uncovered stents for transjugular intrahepatic portosystemic shunt: a randomized controlled trial. J Hepatol. 2014;60:962-8.

19. Yang Z, Han G, Wu Q, Ye X, Jin Z, Yin Z, Qi X, Bai M, Wu K, Fan D. Patency and clinical outcomes of transjugular intrahepatic portosystemic shunt with polytetrafluoroethylene-covered stents versus bare stents: a meta-analysis. J Gastroenterol Hepatol. 2010;25:1718-25.

20. Qi X, Tian Y, Zhang W, Yang Z, Guo X. Covered versus bare stents for transjugular intrahepatic portosystemic shunt: an updated meta-analysis of randomized controlled trials. Therap Adv Gastroenterol. 2017;10:32-41.

21. LaBerge JM, Ring EJ, Gordon RL, Lake JR, Doherty MM, Somberg KA, Roberts JP, Ascher NL. Creation of transjugular intrahepatic portosystemic shunts with the wallstent endoprosthesis: results in 100 patients. Radiology. 1993;187:413-20.

22. Tarantino G, Citro V, Conca P, Riccio A, Tarantino M, Capone D, Cirillo $M$, Lobello $R$, laccarino $V$. What are the implications of the spontaneous spleno-renal shunts in liver cirrhosis? BMC Gastroenterol. 2009;9:89.

23. Tarantino G, Citro V, Esposito P, Giaquinto S, de Leone A, Milan G, Tripodi FS, Cirillo M, Lobello R. Blood ammonia levels in liver cirrhosis: a clue for the presence of portosystemic collateral veins. BMC Gastroenterol. 2009;9:21

24. Tang CM, Yau TO, Yu J. Management of chronic hepatitis B infection: current treatment guidelines, challenges, and new developments. World J Gastroenterol. 2014;20:6262-78.

25. Bissonnette J, Garcia-Pagan JC, Albillos A, Turon F, Ferreira C, Tellez L, Nault JC, Carbonell N, Cervoni JP, Abdel Rehim M, et al. Role of the transjugular intrahepatic portosystemic shunt in the management of severe complications of portal hypertension in idiopathic noncirrhotic portal hypertension. Hepatology. 2016;64:224-31.

26. Berry K, Lerrigo R, Liou IW, loannou GN. Association between Transjugular intrahepatic portosystemic shunt and survival in patients with cirrhosis. Clin Gastroenterol Hepatol. 2016;14:118-23.

27. Bhogal HK, Sanyal AJ. Using transjugular intrahepatic portosystemic shunts for complications of cirrhosis. Clin Gastroenterol Hepatol. 2011;9: 936-46 quiz e123.

28. Colombato $\mathrm{L}$. The role of transjugular intrahepatic portosystemic shunt (TIPS) in the management of portal hypertension. J Clin Gastroenterol. 2007:41(Suppl 3):S344-51.

29. Rossle M, Siegerstetter V, Olschewski M, Ochs A, Berger E, Haag K. How much reduction in portal pressure is necessary to prevent variceal rebleeding? A longitudinal study in 225 patients with transjugular intrahepatic portosystemic shunts. Am J Gastroenterol. 2001;96:3379-83.

30. Casado M, Bosch J, Garcia-Pagan JC, Bru C, Banares R, Bandi JC, Escorsell A, Rodriguez-Laiz JM, Gilabert R, Feu F, et al. Clinical events after transjugular intrahepatic portosystemic shunt: correlation with hemodynamic findings. Gastroenterology. 1998;114:1296-303.

31. Biecker E, Roth F, Heller J, Schild HH, Sauerbruch T, Schepke M. Prognostic role of the initial portal pressure gradient reduction after TIPS in patients with cirrhosis. Eur J Gastroenterol Hepatol. 2007;19:846-52.

32. Membreno F, Baez AL, Pandula R, Walser E, Lau DT. Differences in long-term survival after transjugular intrahepatic portosystemic shunt for refractory ascites and variceal bleed. J Gastroenterol Hepatol. 2005;20:474-81.

33. Riggio O, Nardelli S, Moscucci F, Pasquale C, Ridola L, Merli M. Hepatic encephalopathy after transjugular intrahepatic portosystemic shunt. Clin Liver Dis. 2012;16:133-46.

34. Riggio O, Ridola L, Angeloni S, Cerini F, Pasquale C, Attili AF, Fanelli F, Merli M, Salvatori FM. Clinical efficacy of transjugular intrahepatic portosystemic shunt created with covered stents with different diameters: results of a randomized controlled trial. J Hepatol. 2010;53:267-72.

35. Tan HK, James PD, Sniderman KW, Wong F. Long-term clinical outcome of patients with cirrhosis and refractory ascites treated with transjugular intrahepatic portosystemic shunt insertion. J Gastroenterol Hepatol. 2015:30:389-95.

36. Trebicka J. Emergency TIPS in a child-Pugh B patient: when does the window of opportunity open and close? J Hepatol. 2017:66:442-50.

37. Salerno F, Camma C, Enea M, Rossle M, Wong F. Transjugular intrahepatic portosystemic shunt for refractory ascites: a meta-analysis of individual patient data. Gastroenterology. 2007;133:825-34.

38. Chen H, Bai M, Qi X, Liu L, He C, Yin Z, Fan D, Han G. Child-Na score: a predictive model for survival in cirrhotic patients with symptomatic portal hypertension treated with TIPS. PLoS One. 2013;8:e79637.

39. Fejfar T, Safka V, Hulek P, Vanasek T, Krajina A, Jirkovsky V. MELD score in prediction of early mortality in patients suffering refractory ascites treated by TIPS. Vnitr Lek. 2006:52:771-6.

40. Durand F, Valla D. Assessment of the prognosis of cirrhosis: child-Pugh versus MELD. J Hepatol. 2005:42(Suppl):S100-7.

41. Boyer TD. Transjugular intrahepatic portosystemic shunt: current status. Gastroenterology. 2003;124:1700-10.

42. Clark TW. Management of shunt dysfunction in the era of TIPS endografts. Tech Vasc Interv Radiol. 2008;11:212-6.

43. Sanyal AJ, Freedman AM, Luketic VA, Purdum PP 3rd, Shiffman ML, DeMeo J, Cole PE, Tisnado J. The natural history of portal hypertension after transjugular intrahepatic portosystemic shunts. Gastroenterology. 1997;112:889-98.

44. Bureau C, Garcia-Pagan JC, Otal P, Pomier-Layrargues G, Chabbert V, Cortez C, Perreault P, Peron JM, Abraldes JG, Bouchard L, et al. Improved clinical outcome using polytetrafluoroethylene-coated stents for TIPS: results of a randomized study. Gastroenterology. 2004;126:469-75.

45. Bureau C, Pagan JC, Layrargues GP, Metivier S, Bellot P, Perreault P, Otal P, Abraldes JG, Peron JM, Rousseau H, et al. Patency of stents covered with polytetrafluoroethylene in patients treated by transjugular intrahepatic portosystemic shunts: long-term results of a randomized multicentre study. Liver Int. 2007;27:742-7.

46. Qi X, Tian Y, Zhang W, Zhao H, Han G, Guo X. Covered TIPS for secondary prophylaxis of variceal bleeding in liver cirrhosis: a systematic review and meta-analysis of randomized controlled trials. Medicine (Baltimore). 2016;95:e5680.

47. Riggio O, Angeloni S, Salvatori FM, De Santis A, Cerini F, Farcomeni A, Attili AF, Merli M. Incidence, natural history, and risk factors of hepatic encephalopathy after transjugular intrahepatic portosystemic shunt with polytetrafluoroethylene-covered stent grafts. Am J Gastroenterol. 2008; 103:2738-46.
Ready to submit your research? Choose BMC and benefit from:

- fast, convenient online submission

- thorough peer review by experienced researchers in your field

- rapid publication on acceptance

- support for research data, including large and complex data types

- gold Open Access which fosters wider collaboration and increased citations

- maximum visibility for your research: over $100 \mathrm{M}$ website views per year

At $\mathrm{BMC}$, research is always in progress.

Learn more biomedcentral.com/submissions 